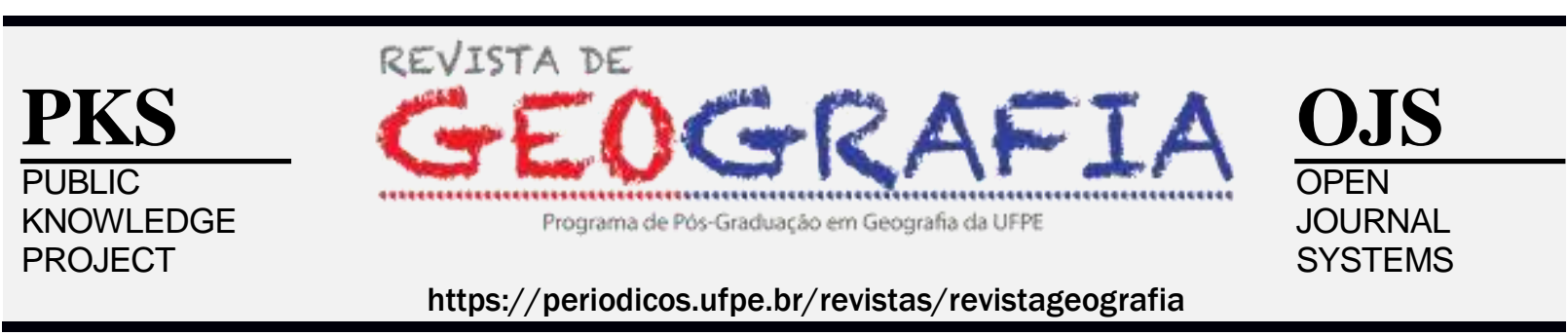

\title{
A MOBILIZAÇÃO DE SABERES NA PRÁTICA DOCENTE DOS PROFESSORES DE GEOGRAFIA NO ENSINO SUPERIOR
}

\author{
Francisco Kennedy Silva dos Santos ${ }^{1}$, Matheus Rivail Alves de Araújo Pereira², Tâmara Carla \\ Gonçalves Bezerra ${ }^{3}$, Thiago Breno de Medeiros Carmo ${ }^{4}$ \\ ${ }^{1}$ Docente do Programa de Pós-Graduaçaõ em Geografia da UFPE: e-mail: francisco.kennedy@ufpe.br. \\ ${ }^{2}$ Bolsita PIBIC/UFPE, Curso de Licenciatura em Geografia: e-mail: matheusrivail2014@gmail.com. \\ ${ }^{3}$ Colaborador do Legep/UFPE: e-mail: tamara.g.bezerra@gmail.com \\ ${ }^{4}$ Colaboradordo Legep/UFPE: e-mail: professorthiagobreno@gmail.com.
}

Artigo recebido em 19/05/2019 e aceito em 26/11/2019

\begin{abstract}
RESUMO
O objetivo do presente trabalho é refletir sobre a formação do docente universitário dos cursos de licenciatura, visando perceber se a prática desse docente corresponde às exigências do mundo contemporâneo em face da legislação brasileira. $\mathrm{O}$ foco principal de nossa investigação é a produção e a mobilização de saberes da experiência na prática docente. Considero como saber da experiência aquele saber oriundo de vivências, sejam pessoais ou profissionais, que o professor mobiliza na sala de aula, os saberes do saber-fazer. Nesse contexto, tomamos inicialmente como categorias de análise o trabalho docente, a formação docente, a epistemologia da prática que permitem focalizar as relações dos professores com os saberes que dominam para poder ensinar e aqueles que ensinam. Para primeira trilha percorrida na investigação, utilizou-se, uma abordagem qualitativa por acreditar que o uso desta análise permite estabelecer conclusões mais significativas, a partir dos dados coletados, bem como da observação direta, in locus, dos sujeitos envolvidos na pesquisa. Os resultados da pesquisa possibilitam afirmar que grande parte dos docentes não possui uma formação pedagógica adequada que atenda as exigências da contemporaneidade. Essa carência pedagógica tem refletido diretamente no cotidiano da sala de aula.
\end{abstract}

Palavras-chave: Geografia; Saberes Docentes; Ensino Superior; Docência.

\section{THE ROLE AND IMPORTANCE OF GEOGRAPHICAL SCIENCE AS A TOOL FOR SOCIAL EMANCIPATION: THE SCHOOL CONTEXT}

\begin{abstract}
The aim of this paper is to reflect on the training of university teachers in undergraduate courses, aiming to understand whether the practice of this teacher corresponds to the demands of the contemporary world in the face of Brazilian legislation. The main focus of our investigation is the production and mobilization of knowledge from experience in teaching practice. I consider how to know from experience that knowledge that comes from experiences, whether personal or professional, that the teacher mobilizes in the classroom, the knowledge of knowhow. In this context, we initially take teaching work, teacher training, the epistemology of practice as the categories of analysis that allow us to focus teachers' relationships with the knowledge they master in order to teach and those who teach. For the first path covered in the investigation, a qualitative approach was used, as it believes that the use of this analysis allows to establish more significant conclusions, based on the data collected, as well as the direct observation, in locus, of the subjects involved in the research. The results of the research make it possible
\end{abstract}


to state that most of the teachers do not have an adequate pedagogical training that meets the demands of contemporary times. This pedagogical deficiency has reflected directly in the classroom.

Keywords: Geography; Teaching Knowledge; University education; Teaching.

\section{OLHANDO OS CENÁRIOS}

A reflexão sobre a prática pedagógica implica a consideração dessa prática sob o ponto de vista do trabalho do professor. Nesse sentido a sociedade do conhecimento é concebida como o ponto em torno do qual giram as análises sobre o trabalho do professor, o ensino. O ensino não é entendido como mera transmissão de conhecimento, mas como uma síntese de saberes que o professor utiliza no seu trabalho profissional.

A crítica à racionalidade técnica, que orientou e serviu de referência para a educação e socialização dos profissionais em geral e dos professores em particular durante grande parte do século XX, gerou uma série de estudos e pesquisas que têm procurado superar a relação linear e mecânica entre o conhecimento técnico-científico e a prática na sala de aula. Os limites e insuficiências dessa concepção levam à busca de novos instrumentos teóricos que fossem capazes de dar conta da complexidade dos fenômenos e ações que se desenvolvem durante atividades práticas.

Segundo Tardif (2002, p.20), “antes mesmo de ensinarem, os futuros professores vivem nas salas de aula e nas escolas e, portanto, em seu futuro local de trabalho". No entanto cabe abrirmos uma discussão para entendermos como os saberes desses profissionais foram construídos e como são mobilizados no âmbito da docência sem deixarmos de considerar o tipo de formação que receberam.

O foco principal desse trabalho é a produção e a mobilização de saberes da experiência na prática docente. Considero como saber da experiência aquele saber oriundo de vivências, sejam pessoais ou profissionais, que o professor mobiliza na sala de aula, os saberes do saberfazer, nas palavras de Therrien e Sousa (2000), articulando com os outros saberes e que "[...] formam um conjunto de representações a partir das quais os professores interpretam, compreendem e orientam sua profissão e sua prática cotidiana em todas as suas dimensões" (TARDIF, 2002, p. 49).

Quando me refiro às vivências pessoais ou profissionais quero dizer que as experiências vividas pelo professor em outras relações pessoais, que não são necessariamente vividas no âmbito escolar, podem ser trazidas para as relações cotidianas em sala de aula e serem 
mobilizadas como saberes na sua prática e também ser articuladas, com outros saberes a partir de uma racionalidade pedagógica e da epistemologia da prática, uma vez que no cenário da educação formal, a atuação do professor aparece marcada por exigências que vão além do domínio dos conteúdos que vai ensinar.

Carvalho (2007, p. 36-37) destaca que para questionarmos sobre qual epistemologia fundamenta a racionalidade pedagógica dos professores dos cursos de Licenciatura, faz-se necessário, a priori, especularmos pelo menos duas categorias: a epistemologia da prática e os saberes docentes. "A razão é decorrente da forma íntima como elas se encontram imbricadas na prática educativa, dificultando limitá-las com exatidão. No entendimento de que a epistemologia da prática incorpora os conceitos de racionalidade pedagógica e o de saberes docentes".

Com base nestes enfoques teóricos, ancoramos a nossa definição de saberes docentes ou saberes da ação docente, entendendo-os com os saberes provenientes do exercício da ação e da profissão docente, os quais o professor manipula para enfrentar as situações advindas do cotidiano.

Como são saberes constituídos pela reflexão, possibilitam, consoante Carvalho (2007), a dinâmica de reconstrução das práticas e podem ser consideradas produtos das mesmas. Se o saber resulta da reflexão e é resultante dela, significa que o saber é fundamentado na racionalidade e na reflexibilidade, "estabelecidas a partir de representações mentais dos sujeitos, de acordo com suas condições de clareza, de precisão e de veracidade" (SACRISTÁN, 1999, p. 50).

Nesse sentido, a reflexão deverá estar a serviço da emancipação e da autonomia profissional do professorado.

Facilitar a conexão de uma concepção da prática docente com um processo de emancipação dos próprios professores, que se encaminhe para uma configuração como intelectuais críticos, requer a constituição de processos de colaboração com o professorado para favorecer sua reflexão crítica. A reflexão crítica não se refere só àquele tipo de mediação que podem fazer docentes sobre suas práticas e as incertezas que estas lhe ocasionam (GHEDIN, 2006, p. 138).

Habermas (1990) defende a auto-reflexão como a possibilidade de trazer à consciência os determinantes de uma forma concreta de estar estruturada a realidade social, processo pelo 
qual, ao fazer-se consciente de tais determinantes, se desfazem seus poderes repressivos sobre a razão.

O processo reflexivo não surge por acaso. Ele é resultado de uma longa trajetória de formação que se estende pela vida, pois é uma maneira de se compreender a própria vida em seu processo (GHEDIN, 2006).

\section{CENÁrio I: o estudo}

O estudo aqui apresentado, de modo mais geral, está situado no tema da docência universitária. De modo mais particular, situa-se no processo de formação e construção de saberes e do trabalho desenvolvidos pelos profissionais dos cursos de Licenciaturas em Geografia sem formação pedagógica, com ênfase na pessoa do professor, seu percurso profissional e sua capacidade de refletir sobre sua própria prática docente.

O tema do professor universitário, no contexto de suas trajetórias, enfatiza sua condição de sujeito e como um dos atores do processo educativo superior. Sem desconsiderar as condições intra e interpessoais que o cercam, busca-se contemplá-las a partir da ótica de como estas são vividas e percebidas pelo docente, considerando-lhe um papel ativo na elaboração e interpretação de seu mundo. A trajetória pessoal desse professor é entendida como o transfundo a partir do qual a vida dos professores adquire consistência e significado existencial.

Em sua prática cotidiana, o professor se depara com situações rotineiras, que exigem o uso de um repertório construído ao longo do tempo, repertório esse baseado em suas experiências e na sua formação e que, ao mesmo tempo, abre inúmeras oportunidades ao professor que se vê diante de situações nunca vividas e, para as quais precisa colocar em funcionamento recursos cognitivos e emocionais pouco ou nunca testados.

Procuramos nessa pesquisa desenvolver uma análise dos saberes docentes no âmbito do trabalho dos professores como profissionais reflexivos, uma vez que nas últimas décadas uma tendência denominada genericamente de formação de professores reflexivos nos permite fazer um exame da situação atual da docência, tendo como referencial a prática docente. Para tanto, procuramos responder o seguinte problema: Qual a relação teoria-prática no trabalho docente desenvolvido pelos professores dos cursos em Licenciatura em Geografia de uma IES pública sem formação pedagógica e como constroem e mobilizam os saberes no âmbito da docência? 
Deste problema surgem, também, outras questões importantes para o trabalho: Como os saberes da experiência são mobilizados na prática docente? Como esses professores conseguem transformar o saber específico que apreenderam durante sua formação num saber ensinável a partir da experiência? De que forma eles atuam nas diversas dimensões educativas e resolvem os problemas que surgem em sua prática cotidiana em sala de aula? Como 'veem" e refletem a sua prática de ensino?

O problema de pesquisa circunscreve-se, portanto, a despeito das bases racionalistas que caracterizam a formação dos professores formados em Geografia e que tiveram apenas contato com saberes específicos a sua profissão. Com este estudo pretendemos alimentar o debate sobre o paradigma do professor reflexivo no contexto da docência do ensino superior.

O profissional assim formado, conforme a análise de Schön (2000), não consegue dar respostas às situações que emergem no dia-a-dia profissional, porque estas ultrapassam os conhecimentos elaborados pela ciência e as respostas técnicas que esta poderiam oferecer ainda não estão formuladas.

Assim, valorizando a experiência e a reflexão na experiência, conforme Dewey, e o conhecimento tácito, conforme Luria e Polonyi, Schön propõe uma formação profissional baseada numa epistemologia da prática, ou seja, na valorização da prática profissional como momento de construção de conhecimento, através da reflexão, análise e problematização desta, e o reconhecimento do conhecimento tácito, presente nas soluções que os profissionais encontram em ato (PIMENTA, 2006, p. 19).

Como objetivo geral da pesquisa, procuramos compreender os elementos constituintes da relação dialética teoria-prática no trabalho docente desenvolvido nos cursos de Licenciatura da área de Geografia de uma IES e dos saberes e suas implicações resultantes para o processo de formação contínua do professor reflexivo crítico.

Para a concretização do objetivo supramencionado definimos os seguintes objetivos específicos: desvelar a trajetória de relação com o saber dos profissionais de ensino observados; caracterizar mecanismos (procedimentos) de 'reflexividade crítica' presentes em situações de trabalho docente; identificar os saberes (de experiência) construídos em práxis de ensino que integra teoria e prática; caracterizar a racionalidade constituinte da gestão dos saberes; investigar como ocorre a transformação pedagógica da matéria. 


\section{CENÁRIO II - o objeto}

A Universidade é uma instituição que tem na instrução sua principal dimensão educativa, educa através da instrução. A crítica ao ensino tradicional, onde o saber ocupava um lugar quase sacralizado, pode explicar o certo abandono pelas questões relacionadas com os saberes ensinados. As pesquisas se concentraram, em grande parte, nas questões relacionadas à aprendizagem. O saber não era discutido, o problema estava no aprender.

Não queremos dizer aqui que as pesquisas sobre aprendizagem não são necessárias. Certamente elas precisam ser desenvolvidas e oferecem contribuições relevantes para a compreensão dos processos educativos. No entanto, defendemos que investigar a epistemologia do conhecimento docente e da prática do professor é fundamental e estratégico para compreensão dos processos em jogo. Negá-la ou esquecê-la nos faz correr o risco de cair no retrocesso de propostas espontaneístas/populistas ou autoritárias para a educação.

Tomamos como espaço para realização da pesquisa uma Instituição de Ensino Superior (IES) pública, estadual, identificada com a missão de formar profissionais cada vez mais orientados para a solução dos grandes problemas do semi-árido e para enfrentar os desafios da modernidade. Esta IES apresenta, em sua estrutura organizacional, órgãos da Administração Superior, órgãos da Administração Intermediária e órgãos da Administração Básica.

Nesse contexto, nossos olhares são direcionados para os órgãos da Administração Intermediária constituídos pelos Centros e Faculdades que têm por finalidade supervisionar, mediar, integrar e assessorar as atividades de ensino, pesquisa e extensão, em campos de conhecimentos específicos, delimitados administrativamente.

Devido a temporalidade da pesquisa, decidimos, como delimitação do campo de estudo, investigar o trabalho docente dos professores do curso de licenciatura em Geografia. Tal escolha perpassa as especificidades de cada curso, considerando sua relação com outras áreas do conhecimento, como é o caso das Ciências da Educação.

Diante da complexidade do objeto optamos pela pesquisa qualitativa considerada o caminho mais indicado a trilhar, uma vez que esta privilegia os significados, experiências, motivos, sentimentos, atitudes e valores dos professores envolvidos com o fenômeno a ser investigado: a docência no ensino superior na perspectiva de professores formados em áreas não pedagógicas. Este modelo de pesquisa condiz mais com o tipo de problema deste estudo, 
uma vez que "ela aborda o conjunto de expressões humanas constantes nas estruturas, nos processos, nos sujeitos, nos significados e nas representações” (MINAYO, 1996, p.15).

Nossa abordagem é qualitativa porque, consoante Carvalho (2007, p.29):

não é possível estudar a racionalidade pedagógica de forma fragmentada tendo em vista seus componentes apresentarem-se complexo no contexto diário. Ao invés disso, fornece uma visão holística do fenômeno investigado, levando em conta a relação de reciprocidade entre seus componentes diante da totalidade da situação.

Neste contexto a pesquisa qualitativa, rompe com os parâmetros epistemológicos do paradigma positivista, incorporando em seu fazer, o sujeito e sua subjetividade; valorizando a construção peculiar das práticas cotidianas, que passam a ser vistas, não por seus produtos palpáveis, objetivados, quantitativos, mas pelo processo significativo de sua construção, onde se incorpora as representações, os significados e o sentido existencial elaborado. Aproximamonos, portanto da etnometodologia e da ergonomia do trabalho docente.

Etnometodológica porque o objeto de estudo impõe a realização de uma pesquisa de campo, em que os dados serão coletados in loco, não para serem testados, mas sim interpretados e conceitualizados.

A opção pela utilização da ergonomia do trabalho docente como um dos instrumentos de análise se dá em função da necessidade de melhor compreender o trabalho concreto dos professores enquanto profissionais reflexivos, a fim de se construir um entendimento da dinâmica da docência.

Segundo Therrien e Loiola (2001), a ergonomia, aplicada aos estudos no campo da educação, interessa-se pela investigação da dinâmica que considera o sujeito, a atividade e o contexto como um todo. De modo mais específico, trata-se de um ponto de vista centrado no desenvolvimento dos conhecimentos em contexto. Nessa perspectiva, o ensino é uma "situação situada", ou seja, uma atividade complexa cujo objetivo é a adaptação a uma situação. O ensino é um processo de trabalho constituído de diferentes componentes, entre eles o objetivo do trabalho, o objeto do trabalho, as técnicas e os saberes dos trabalhadores, o produto do trabalho, os próprios trabalhadores e seu papel no processo de trabalho. 


\section{CENÁRIO III - primeiros achados}

Um aspecto a destacar nos cursos investigados é a importância secundária das disciplinas pedagógicas frente às disciplinas específicas, causando uma visão distorcida do curso, apresentando-se esse mais como um curso que forma, exclusivamente, bacharéis. Tal fato pode ser compreendido pela histórica situação de desprestígio social da profissão de professor, assim como pela constante predominância de bacharéis e engenheiros entre os docentes do curso.

Tais formadores de professores, por desconhecimento de estudos sobre ensino de geografia, mantêm-se no nível do "senso comum" docente, considerando o processo de ensino de geografia como algo simples, desde que se tenha um bom conhecimento da matéria.

A articulação entre as disciplinas de conteúdo pedagógico e as de conteúdo geográficos é um ponto que precisa ser, efetivamente, implementado no processo de formação do licenciado em geografia. Para isso é necessário um esforço conjunto de todos os envolvidos no processo de formação: professores desses cursos, do Centro de Educação e dos alunos da Licenciatura em plena atividade profissional, no sentido de se buscar uma maior interação e integração entre os conhecimentos geográficos, os conhecimentos pedagógicos e aqueles oriundos de pesquisas na área de ensino de geografia.

Existe uma falta de identidade própria para o curso de formação de professores, uma vez que funcionam como anexos do curso de bacharelado, aproveitando disciplinas e professores comuns. A formação de professores deve ser realizada como um processo autônomo, numa estrutura com identidade própria, distinta dos cursos de bacharelado.

Vale lembrar que o ensino dos componentes curriculares/disciplinas tem se reduzido à transmissão de informações, definições e conceitos isolados, sem qualquer relação com a vida do aluno, exigindo deste quase sempre a pura memorização, restrita a baixos níveis cognitivos. Transforma-se, muitas vezes, a linguagem geográfica, uma ferramenta, no fim último do conhecimento. Reduz-se o conhecimento geográfico a categorias isoladas, que devem ser exaustivamente treinadas, supondo a mecanização e não o entendimento de uma situaçãoproblema privilegiando aspectos teóricos, em níveis de abstração.

Para desenvolver a docência universitária, é fundamental que o docente seja capaz de perceber, entender, analisar e acompanhar as mudanças que ocorrem no ensino superior na contemporaneidade. 


\section{REFERÊNCIAS}

CARVALHO, Antonia Dalva França. A racionalidade pedagógica da ação dos formadores de professores: um estudo sobre a epistemologia da prática docente nos cursos de licenciatura da Universidade Federal do Piauí. Tese (Doutorado em Educação), Programa de Pós-Graduação em Educação Brasileira, Universidade Federal do Ceará, Fortaleza, 2007.

GHEDIN, Evandro. Professor reflexivo: da alienação da técnica à autonomia da crítica. In: PIMENTA, S. G. e GHEDIN, E. Professor reflexivo no Brasil: gênese e crítica de um conceito, (orgs.). - 4. ed. São Paulo: Cortez, 2006.

HABERMAS, Jürgen. Pensamento pós-metafísico: estudos filosóficos. Rio de Janeiro, Tempo e Presença, 1990.

MINAYO, M.C.S. (Org.) Pesquisa Social: teoria, método e criatividade. Petrópolis, RJ: Vozes, 1994.

PIMENTA, S. G. Professor Reflexivo: construindo uma crítica. In: PIMENTA, S. G. e GHEDIN, E. Professor reflexivo no Brasil: gênese e crítica de um conceito, (Orgs.). 4. ed. São Paulo: Cortez, 2006.

SACRISTÁN, José G. Poderes instáveis em educação. Tradução Beatriz Afonso Neves, Porto Alegre, RS: Artes Médicas, 1999.

SAMPAIO, M. das Mercês F. A escola no centro da pesquisa: caminhos e problemas. In. Anped, 26ª Reunião Anual, Poços de Caldas, 2003.

SARMENTO, Manuel Jacinto. A vez e a voz dos professores: contributo para o Estudo da Cultura Organizacional da Escola Primária. Lisboa: Porto Editora, 1993.

SCHÖN, Donald Educando o profissional reflexivo: um novo design para o ensino e a aprendizagem. Porto Alegre: Artmed, 2000.

SERRÃO, Maria Isabel Batista. Superando a racionalidade técnica na formação: sonho de uma noite de verão. In: PIMENTA, S. G. e GHEDIN, E. Professor reflexivo no Brasil: gênese e crítica de um conceito, (Orgs.). - 4. ed. São Paulo: Cortez, 2006.

TARDIF, M. Saberes docentes e formação de professores. São Paulo: Vozes, 2002.

THERRIEN, J. e LOIOLA, Francisco Antonio. Experiência e competência no ensino: pistas de reflexões sobre a natureza do saber-ensinar na perspectiva da ergonomia do trabalho docente. Educação \& Sociedade, ano XXII, n 74, Abril/2001. 
THERRIEN, J. e SOUSA, Ângela. Cultura docente e gestão pedagógica: a racionalidade prática dos saberes do saber-fazer racionalidade do agir docente - elementos para uma análise da formação prática. In. NOBRE, M. D. e THERRIEN, J. (Org.). Artesãos de um outro ofício: múltiplos saberes e práticas no cotidiano escolar. São Paulo: Annablume: Fortaleza, 2000. 